\title{
Foreword
}

\section{ALL or None?}

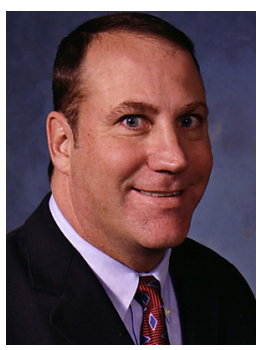

Mark D. Miller, MD Consulting Editor

The debate regarding the existence, function, location, and reconstruction of the anterolateral ligament (ALL) of the knee continues. Because of his tremendous experience in anterior cruciate ligament (ACL) reconstruction, and his active role in this debate, I invited my mentor, Dr Freddie Fu, to put together a treatise on this subject. He invited an international consortium of ACL experts to make their case. He has covered all aspects without any bias, leaving it up to you, the reader, to make the call. I personally believe that there is some importance to anterolateral structures in ACL instability, regardless of what you call it, but, like many of you, I have not fully committed to performing ALL reconstruction in most patients. There may be a role in complex revision procedures with significant rotatory instability, but it remains unclear whether an ALL reconstruction with a free graft or a tenodesis of a portion of the iliotibial band is the best option. There is much study currently underway, and we should all carefully follow this research and continue to ask questions as we continue to seek the best for our patients.

Mark D. Miller, MD

S. Ward Casscells Professor

Division of Sports Medicine Department of Orthopaedic Surgery

University of Virginia 400 Ray C. Hunt Drive, Suite 330 Charlottesville, VA 22908-0159, USA

E-mail address: mdm3p@virginia.edu 